\title{
Sistem Kontrol Suhu dan Pendeteksi Gerakan Pada Ruangan Laboratorium Berbasis Arduino Uno R3 Dengan Modul Real Time Clock (RTC) dan Passive Infrared Receiver (PIR)
}

\section{(Studi Kasus : Laboratorium Politeknik Sains \& Teknologi Wiratama Maluku Utara)}

\author{
Julkifli Muksin ${ }^{1}$, Munawir A. Hi Musa ${ }^{2}$, Arisandy Ambarita ${ }^{3}$, Adelina Ibrahim ${ }^{4}$, Sitna Hajar Hadad \\ ${ }^{1,2}$ Program Studi Teknik Komputer, Politeknik Sains \& Teknologi Wiratama Maluku Utara \\ ${ }^{4}$ Program Studi Teknik Informatika, Universitas Muhammadiyah Maluku Utara \\ ${ }^{5}$ Program Studi Teknik Komputer, Akademi Ilmu Komputer (Aikom) Ternate \\ e-mail: Asrilmuksin393@gmail.com
}

\begin{abstract}
Abstrak
Tujuan Penelitian ini adalah merancang Sistem kontrol suhu dan pendeteksi gerakan dalam ruangan laboratorium berbasis arduino uno R3 dengan modul Real Time Clock (RTC) dan Passive Infrared Receiver (PIR). Dalam penelitian ini metode yang digunakan adalah SDLC dan alat bantu perancangan menggunakan Flowchart, fritzing. Sistem pengontrolan suhu dan Pendeteksi Gerakan dalam ruangan yang dirancang mengunakan komponen utama terdiri dari mikrokontroler, sensor suhu (DHT22), sensor gerak (PIR), modul RTC, LCD, relay, dan kipas. Pengujian sesor PIR dengan jarak 1-5 meter dengan waktu yang digunakan dari 0-90 detik sensor masi mendeteksi adanya pergerakan, dengan adanya pergerakan yang terdeteksi oleh sensor PIR maka Relay aktif kipas berputar, kemudian LCD sebagai indikator menampilkan kipas ON dan ada pergerakan keterangan ruangan sedang ada orang. pengujian sensor PIR terhadap kepekaan sudut sekeliling ruangan, pengujian dimulai dari nilai sudut $0^{\circ}-45^{\circ} 1-4$ meter PIR masih mendeteksi adanya Pergerakan. Selain itu pengujian sensor DHT22 dengan suhu normal $28^{\circ} \mathrm{C}$, Sistem ini dapat membantu pihak kampus dalam mengontrol suhu dan mendeteksi gerakan dalam ruangan secara otomatis
\end{abstract}

Kata kunci: Pengontrolan, Suhu, Gerakan, Arduino Uno

\begin{abstract}
The purpose of this research is to design a temperature control system and motion detection in a laboratory room based on Arduino Uno R3 with Real-Time Clock (RTC) and Passive Infrared Receiver (PIR) modules. In this study, the method used is SDLC and design tools using flowcharts, fritzing. Indoor temperature control and motion detection systems are designed using the primary components consisting of a microcontroller, temperature sensor (DHT22), a motion sensor (PIR), RTC module, LCD, relay, and fan. Testing the PIR sensor with a distance of 1-5 meters with the time used from 0-90 seconds, the sensor still detects movement. With the motion detected by the PIR sensor, the active relay fan rotates. The LCD as an indicator displays the fan ON. There is the movement of room information. There are people. Testing the PIR sensor on the corner's sensitivity around the room, the test starts from an angle value of $0^{\circ}-45^{\circ} 1-4$ meters. PIR still detects movement. In addition to testing the DHT22 sensor with an average temperature of $28^{\circ} \mathrm{C}$, this system can automatically help the campus control temperature and automatically detect indoor movement.
\end{abstract}

Keywords: Control, Temperature, Movement, Arduino Uno 


\section{PENDAHULUAN}

Alat pengontrol suhu sangat banyak diperlukan dalam hal-hal tertentu. Seperti ruangan kerja perkantoran, ruangan rapat, ruangan perpustakaan dan yang menjadi titik fokus peneliti adalah ruangan Laboratorium Politeknik Sains \& Teknologi Wiratama Maluku Utara.

Suhu suatu ruangan sangat berpengaruh pada efektivitas kegiatan atau dalam pekerjaan. Bekerja pada lingkungan yang terlalu panas dapat menurunkan kemampuan fisik tubuh dan dapat menyebabkan keletihan terlalu dini sedangkan pada ruangan yang terlalu dingin, dapat menyebabkan hilangnya fleksibilitas terhadap alat-alat motorik tubuh yang disebabkan oleh timbulnya kekakuan fisik tubuh.

Menurut Keputusan Mentri Kesehatan Republik Indonesia Nomor 1405/Menkes/SK/XI/2002 mengenai Persyaratan Kesehatan Lingkungan Kerja Perkantoran dan Industri, bahwa persyaratan udara ruangan yang baik memiliki range suhu berkisar $18{ }^{\circ} \mathrm{C}-28{ }^{\circ} \mathrm{C}$ dan kelembaban udara 40\%-60\%. Apabila suhu udara di atas $28{ }^{\circ} \mathrm{C}$ maka diperlukan suatu alat pengontrolan, seperti kipas angin atau AC (Air Conditioner) (Menkes RI, 2002).

Sistem pengontrolan suhu berperan penting untuk mengetahui perubahan suhu dalam suatu ruangan di sisi lain perubahan suhu berpengaruh terhadap tubuh manusia di dalam ruangan sehingga dapat diketahui keadaan suhu dalam suatu ruangan juga berdasarkan terhadap keberadaan orang dalam ruangan tersebut. Politeknik Sains \& Teknologi wiratama Maluku Utara memiliki ruangan laboratorium tempat praktek Software dan Hardware. Berdasarkan observasi penelitian ruangan labolatorium belum memiliki alat pengontrol suhu dan monitoring keberadaan orang dalam ruangan hal ini karena tidak adanya alat pengontrolan suhu dan keberadaan orang dilaboratorium sehingga dianggap kurang efisien. Laboratorium hanya memiliki satu AC dan pengoprasiannya masih manual ketika banyak mahasiswa yang masuk ke dalam ruangan suhu dalam ruangan akan naik dalam ruangan panas maka AC.

Berdasarkan uraian tersebut maka diperlukan sistem control suhu ruangan dengan mendeteksi keberadaan orang dalam ruangan secara otomatis

\section{Rumusan Masalah}

Berdasarkan latar belakang di atas, maka masalah dalam penelitian ini dirumuskan sebagai berikut: Bagaimana merancang sistem pengontrolan suhu dan pendeteksi keberadaan orang dalam ruangan laboratorium berbasis arduino uno R3 dengan modul Real Time Clock (RTC) dan Passive Infrared Receiver (PIR) di Politeknik Sains \& Teknologi Wiratama Maluku Utara.

\section{Tujuan Penelitian}

Penelitian ini bertujuan untuk: Merancang Sistem kontrol suhu dan pendeteksi gerakan dalam ruangan laboratorium berbasis arduino uno R3 dengan modul Real Time Clock (RTC) dan Passive Infrared Receiver (PIR)

\section{Manfaat Penelitian}

Penelitian ini diharapkan dapat memberikan manfaat baik secara teoritis maupun secara praktis:

1. Manfaat teoritis: penelitian ini dapat memberikan pengetahuan bagi peneliti dan khalayak umum tentang 
perancangan sistem pengontrolan suhu dan pendeteksi gerakan pada ruangan.

2. Membantu Pihak Kampus untuk dapat mengontrol suhu dan mendeteksi gerakan pada ruangan laboraturium secara otomatis

\section{Tinjauan Pustaka}

Menurut penelitian sebelumnya yang dilakukan oleh Muhammad Ridha Fauzi dan Harun Mukhtar (2016), dengan judul Rancang Bangun Sistem Pengaturan Temperatur Ruangan Menggunakan Sensor DHT11 Berbasis Mikrokontroler Arduino. Temperatur suatu ruangan dapat dikontrol untuk menghasilkan suasana yang menyejukkan. Untuk memperoleh suasana ruangan yang menyejukkan dapat menggunakan perangkat Air Conditioner (AC). Namun Pengontrolan temperatur ruangan selama ini dilakukan secara manual menggunakan sebuah peralatan tambahan yang dinamakan remote contol, dimana pengunaan remote control masih sedikit merepotkan dikarenakan apabila suhu suatu ruangan berubah-ubah maka kita perlu mengseting AC agar suhu dalam ruangan sesuai keinginan kita. Oleh karena itu dibuat lah suatu sistem pengontrolan temperatur ruangan mengunakan Sensor DHT11 berbasis Mikrokontroler Aduino, yang bisa mengontrol suhu ruangan sesuai keinginan kita tampa harus menyeting mengunakan remote control dikarenakan Alat ini bekerja secara otomatis sesuai perintah yang telah di seting atau program yang telah dibuat dan dimasuk kedalam alat tersebut.

Menurut Arief Goeritno dkk, dengan judul Implementasi Sensor DHT11 Untuk Pengkondisian Suhu dan Kelembaban Relatif Berbantuan Mikrokontroler. Pengunaan sensor suhu dan Mikrokontroler Arduino sangat efisien dikarenakan setiap alat/sensor yang dihubungkan kemikrokontroler harus melakan pengintegrasian antara alat/sensor dan Mikrokontroler. Kemudian Mikrokontroler Arduino Mengunakan bahasa pemograman tersendiri yaitu bahasa $\mathrm{C}++$ yang sangat mudah dipelajari dikarenakan Mikrokontroler yang bersifat Open Source.

\section{LANDASAN TEORI \\ Pengertian Sistem}

Sistem adalah rangkain dari dua atau lebih komponen-komponen yang saling berhubungan, yang berinteraksi untuk mencapai suatu tujuan. Sebagian besar sistem terdiri dari subsistem yang lebih kecil yang mendukung sistem yang lebih besar (Romney dan Steinbart, 2015).

\section{Krakteristik Sistem}

Karakteristik sistem adalah sistem yang mempunyai komponen-komponen, batas sistem, lingkungan sistem, penghubung, masukan, keluaran, pengolah dan sasaran. Untuk lebih jelasnya dapat dilihat pada gambar 2.1 di bawah ini yang merupakan karakteristik sistem.

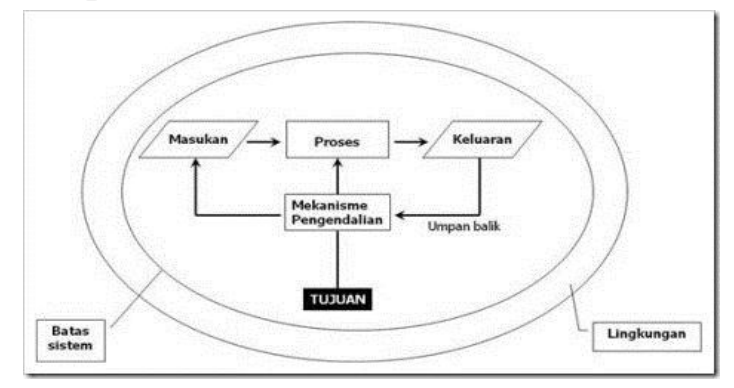

Gambar 1 Krakteristik Sistem (Sumber: Wodpress)

\section{Pengertian Arduino}

Arduino adalah kit elektronik atau papan rangkaian elektronik open source yang di dalamnya terdapat komponen 
utama, yaitu sebuah chip mikrokontroler dengan jenis $A V R$ dari perusahan Atmel. Mikrokontroler itu sendiri adalah chip atau IC (integrated circuit) yang bisa di program menggunakan komputer. Tujuan menanamkan program pada mikrokontroler adalah agar rangkaian elektronik dapat membaca input, memproses input tersebut dan kemudian menghasilkan output sesuai yang diinginkan. Jadi mokrokontroler bertugas sebagai otak yang mengendalikan input, proses dan output sebuah rangkaian elektronik (Syawil. ST., MT. 2015).

\section{METODE PENELITIAN}

Metode pemelitian adalah tahapan yang dilakukan untuk memperoleh setiap tujuan penelitian

Penelitian ini mengunakan jenis data primer dan sekunder. Data primer adalah data yang diperoleh langsung di lokasi penelitian. Data primer dalam penelitian ini berupa kondisi ruangan laboratorium Politeknik Wiratama, diperoleh pada laboratorium poltek wiratama. Data sekunder adalah data pendukung yang diperoleh dari pihak kedua. Data sekunder dalam penelitian ini berupa, sejah singkat, struktur organisasi, visi, misi dan tujuan. Data ini diperoleh dari Kampus Politeknik Wiratama. Kemudian metode pengumpulan data terbagi menjadi tiga bagian Studi Pustaka, Opservasi, dan Wawancara. Dan metode pengembangan sistem mengunakan metode System Development Life Cycle (SDLC). SDLC adalah metode yang populer dikalangan analisis maupun Programmer selain itu SDLC merupakan metode yang menggunakan pendekatan sistem yang disebut pendekatan air terjun (waterfall) dimana setiap tahapan sistem akan dikerjakan secara berurut menurun dari perencanaan, analisa, desain, implementasi, dan perawatan.

\section{Indentifikasi masalah dan studi literatur.}

Tahap awal yang dilakukan sebelum melakukan penelitian adalah identifikasi masalah, pada tahap ini peneliti mengawalinya dengan melakukan pengamatan langsung di lapangan, untuk mengetahui kondisi nyata yang ada di Laboratorium software Politeknik Sains Teknologi Wiratama Maluku utara. Tahapan ini bertujuan untuk mencari tahu dan mengindentifikasikan kendala-kendala atau masalah yang dihadapi di lapangan. Studi literatur dilakukan untuk memperoleh referensi-referensi yang akurat untuk menyelesaikan permasalahan yang diteliti.

\section{Analisis dan definisi kebutuhan.}

Padan tahap analisis merupakan tahap mengindentifikasi permasalahan sistem yang ada di ruangan Laboratorium software Politeknik Sains \& Teknologi Wiratama Maluku Utara, untuk mengembangkan atau membuat sistem yang baru, berupa sistem pengontrolan suhu ruangan otomatis. Definisi kebutuhan dalam penelitian ini berupa kebutuhan perangkat keras (Hardware) dan perangkat lunak (Software).

\section{Perancangan Sistem dan Perangkat Lunak.}

Berdasarkan analisis pada proses sistem, maka rancangan sistem pada penelitian ini ialah mendesain flowchart sistem yang diusulkan dan Diagram Blok Sistem. Perancangan sistem pada tahap ini menjadi dua yaitu perancangan perangkat keras (Hardware) dan perangkat lunak (Software). 


\section{Perancangan Perangkat Keras.}

Pada tahap ini rancangan perangkat keras meliputi:

1. Rangkain LED dan Board Arduino

2. Rangkaian $L C D$ dan Board Arduino

3. Rangkain RTC dan Board Arduino

4. Rangkain Sensor PIR dan Board Arduino

5. Rangkain Sensor DHT22 dan Board Arduino

6. Rangkain Relay, kipas dan Board Arduino

\section{Perancangan Perangkat Lunak.}

Rancangan perangkat lunak pada tahapan ini adalah membuat skema keseluruhan perankat keras dengan menggunakan Aplikasi Fritzing dan Arduino Ide (Integrated Development Environment) sebagai text editor untuk mengedit, mengeksekusi dan memvalidasi kode program dan mengupload kode program ke board arduino.

\section{Implementasi dan Pengujian Unit.}

Pada tahapan ini untuk mengimplementasikan Rancang bangun Sistem Pengontrolan Suhu Ruangan Laboratorium Berbasis Arduino Uno R3 Dengan Menggunakan Modul RTC dan PIR membutuhkan Software Arduino IDE, untuk membuat kode program. Pengujian Unit (Unit Testing) berdasarkan pada perancangan perangkat lunak secara rinci dengan cara pengecekan keseluruhan kode program. Adapun pengujian unit pada penelitian ini yaitu:

a. Pengujian kode program $L E D$

b. Pengujian kode program $L C D$

c. Pengujian kode program $R T C$

d. Pengujian kode program PIR e. Pengujian kode program sensor DHT22

f. Pengujian kode program Relay

\section{Integrasi dan Pengujian Sistem}

Pada tahap ini pengujian sistem di lakukan pada ruangan laboratorium software Politeknik Sains \& Teknologi Wiratama Maluku Utara dengan pengujian pada kepekaan sudut dan jarak sensor PIR dengan sudut 0 sampai 60 derajat dan jarak 1 sampai 5 meter dan juga pengujian pada sensor DHT22 dengan suhu normal 28 derajat celcius.

\section{Operasi dan Pemiliharaan.}

Pada tahapan ini operasi dan pemeliharaan, yang dimaksud dengan operasi dan pemeliharaan adalah setelah semua tahapan yang telah dijelaskan di atas. Kemudian alat yang telah dibuat kemudian digunakan dalam ruangan laboratorium dan berjalan sesuai dengan keingina peneliti maka peneliti membuat jadwal. Untuk operasi dan pememiliharan yang terjadwal terhadap alat yang telah dijalankan dalam ruangan laboratorium.

\section{Alur Penelitian}

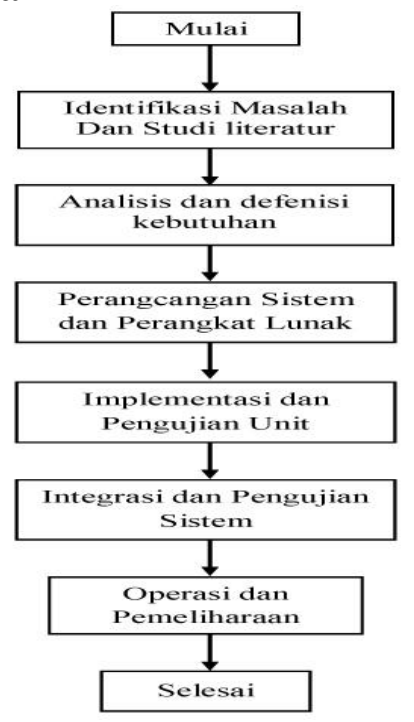


Gambar 2 Alur Penelitian

(Sumber : Olahan Peneliti)

\section{ANALISIS DAN PERANCANGAN Analisis Sitem Yang Berjalan}

Analisa sistem yang berjalan merupakan langkah atau proses yang menunjukan perjalanan pada suatu sistem yang berjalan atau berlangsung. Tujuan dari penelitian ini adalah untuk mengetahui gambaran secara jelas mengenai sistem yang berjalan pada ruangan laboratorium software Politeknik Sains \& Teknologi Wiratama Maluku Utara.

\section{Sistem Yang Diusulkan}

Berdasarkan kelemahan-kelemahan yang terdapat pada sistem yang berjalan dapat diusulkan sistem yang baru yaitu, Sistem Pengontrolan Suhu dan Pendeteksi Gerakan Pada Ruangan Berbasis Arduino Uno $R 3$ dengan menggunakan Modul RTC (Real Time Clock) dan Sensor PIR (Passive Infrared Receiver). Dengan adanya sistem yang diusulkan, dapat meminimalisir kekurangan sistem yang berjalan. Berikut ini adalah diagram sistem yang diusulkan serta keterang dan kelebihan sistem.

\section{Diagram Flowchart Sistem Yang Diusulkan}

Diagram Flowchart Sistem yang diusulkan merupakan desain umum untuk mengetahui gambaran sistem yang akan dibuat, berikut adalah gambar flowchart sistem yang diusulkan:

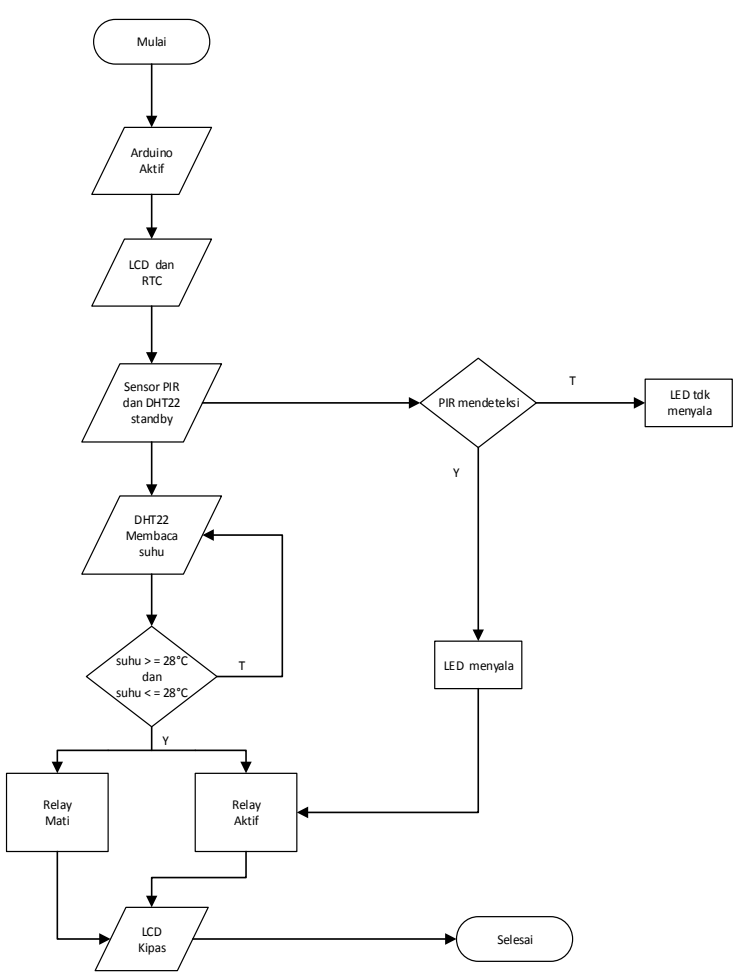

Gambar 3 Alur Sistem yang diusulkan (Sumber : Olahan Peneliti)

\section{Perancangan Diagram Blok Sistem}

Pada bagian ini Gambaran keseluruahan sistem yang dibagun dalam bentuk diagram blok sebagai berikut.

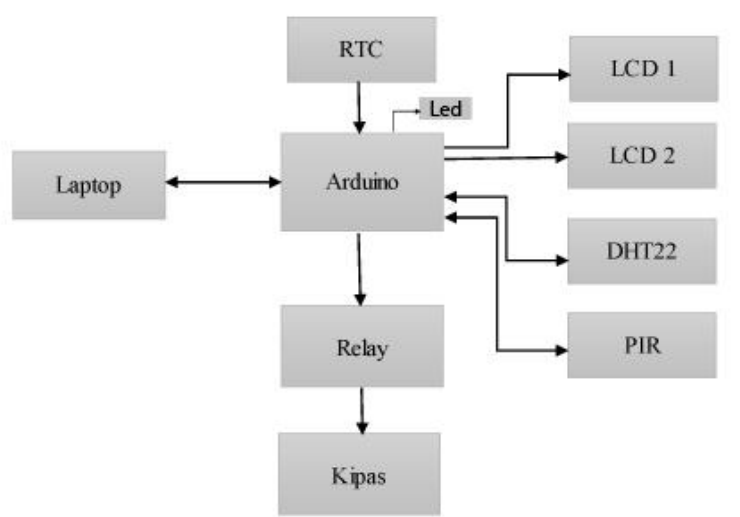

Gambar 4. Diagram blok rangkaian sistem (Sumber : Olahan Peneliti)

Dalam rancangan blok rangkaian sistem terdapat sambungan antar komponen yang dalam diagram blok 


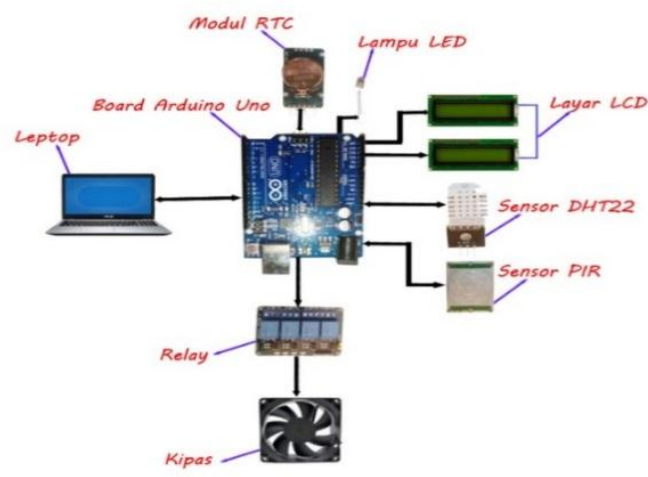

Gambar 5 Diagram Blok Rangkaian Sistem

(Sumber: Olahan Peneliti)

\section{Rangkaian Keseluruhan Perangkat Keras (Hadware)}

Rangkaian keseluruhan sistem pada penelitian ini merupakan akhir dari seluruh rangkaian hadware. Berikut adalah bentuk dari skema keseluruhan hadware.

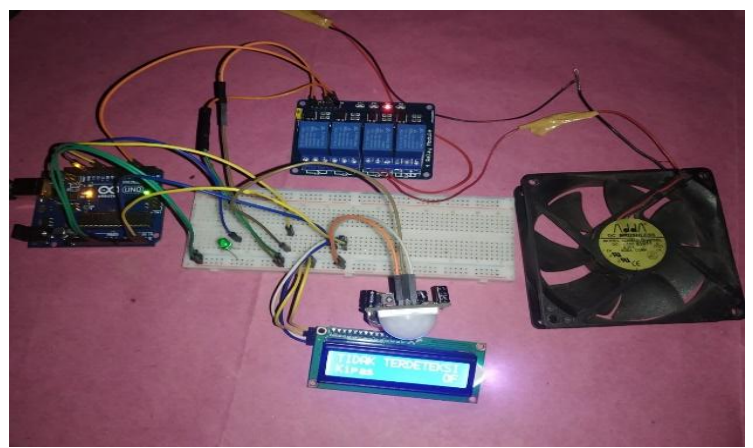

Gambar 6 Rangkaian Perangkat (Sumber: Olahan Peneliti)

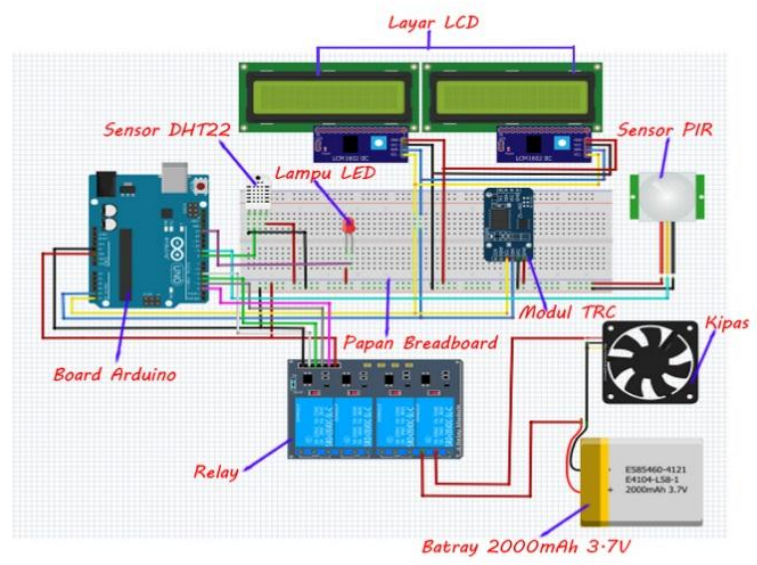

Gambar 7 Skema rankaian keseluruhan hardware

(Sumber data: Olahan peneliti)

\section{IMPLEMENTASI DAN PEMBAHASAN Pengujian Sistem}

Pengujian sistem merupakan hal terpenting yang perlu dilakukan untuk menemukan kesalahan dan kekurangan pada sistem yang telah dibuat. Pengujian tersebut bertujuan untuk mengetahiu apakah sitem yang dibuat sudah memenuhi kriteria sesuai dengan perancangan sistem. Pada tahapan ini peneliti menguji hardware berserta kode program yang digunakan. Berikut ini adalah pengujian hardware dan programnya.

\section{Pengujian sensor PIR (Passive Infared Receiver)}

PIR adalah sensor deteksi gerak (Motion Detector), yang akan mendeteksi gerakan ketika ada orang di dalam laboratorium kemudian mengaktifkan relay dan kipas pun menyala. Di bawa ini adalah gambar pengujian sensor PIR dan kode programnya.

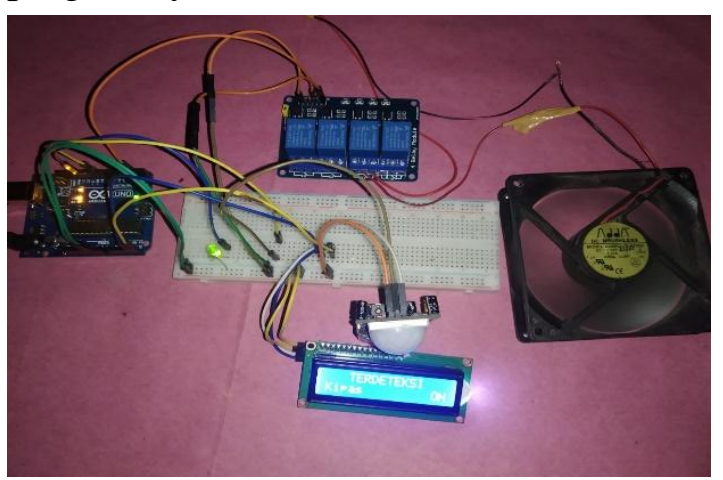

Gambar 8 Rangkaian pengujian sensor $P I R$ dalam keadan tidak terdeteksi pergerakan (Sumber: Olahan peneliti) 


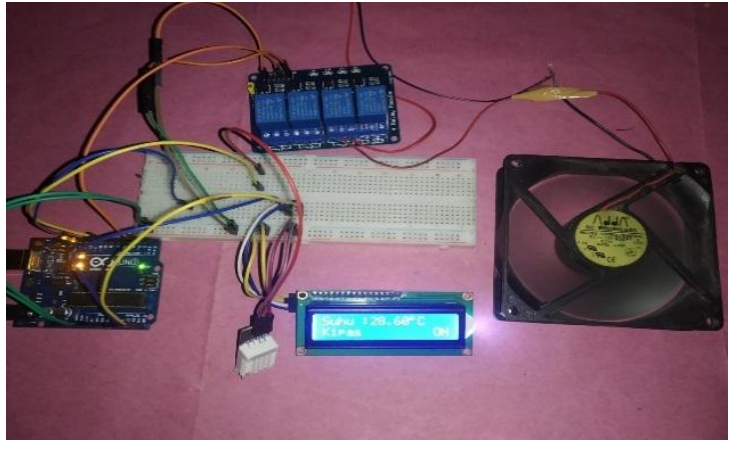

Gambar 9 Rangkaian pengujian sensor PIR dalam keadan terdeteksi pergerakan (Sumber: Olahan peneliti)

Table 1 Hasil pengujian saat ada gerakan pada sensor PIR

\begin{tabular}{|c|c|c|c|c|c|}
$\begin{array}{c}\text { Jarak } \\
\text { Sensor PIR }\end{array}$ & $\begin{array}{c}\text { Lampu } \\
\text { LED }\end{array}$ & Relay, Kipas & LCD & Keterangan & $\begin{array}{c}\text { Kondisi } \\
\text { Ruangan }\end{array}$ \\
\hline 1 Meter & Menyala & AktifBerputar & Kipas On & Terdeteksi & Ada Orang \\
\hline 2 Meter & Menyala & AktifBerputar & Kipas On & Terdeteksi & Ada Orang \\
\hline 3 Meter & Menyala & AktifBerputar & Kipas On & Terdeteksi & Ada Orang \\
\hline 4 Meter & Menyala & AktifBerputar & Kipas On & Terdeteksi & Ada Orang \\
\hline 5 Meter & Menyala & AktifBerputar & Kipas On & Terdeteksi & Ada Orang \\
\hline \multicolumn{5}{c}{ (Sumber: Olahan Peneliti) } \\
\hline \multicolumn{5}{|c}{}
\end{tabular}

\section{Pengujian sensor DHT22}

DHT22 merupakan sensor suhu yang akan digunakan untuk mengukur suhu di ruangan laboratorium dan dikombinasikan dengan sensor PIR untuk menyalakan kipas. Berikut adalah gambar rangkaian pengujian dan kode program dari sensor DHT22.

Table 2. Hasil pengujian sensor DHT22 pada siang hari

\begin{tabular}{|c|c|c|c|c|}
\hline No & $\begin{array}{c}\text { Detik } \\
\text { (Sekon) }\end{array}$ & $\begin{array}{c}\text { DHT22 } \\
\text { (Celcius) }\end{array}$ & $\begin{array}{c}\text { LCD } \\
\text { (Indikator) }\end{array}$ & $\begin{array}{c}\text { Kipas } \\
\text { (Pendingin) }\end{array}$ \\
\hline 1 & 0 & 28.00 & Off & Mati \\
\hline 2 & 10 & 28.10 & On & Hidup \\
\hline 3 & 20 & 28.20 & On & Hidup \\
\hline 4 & 30 & 28.40 & On & Hidup \\
\hline 5 & 40 & 28.50 & On & Hidup \\
\hline 6 & 50 & 28.70 & On & Hidup \\
\hline 7 & 60 & 29.00 & On & Hidup \\
\hline 8 & 70 & 29.20 & On & Hidup \\
\hline 9 & 80 & 29.10 & On & Hidup \\
\hline 10 & 90 & 29.50 & On & Hidup \\
\hline 11 & 100 & 29.70 & On & Hidup \\
\hline 12 & 110 & 29.80 & On & Hidup \\
\hline 13 & 120 & 30.10 & On & Hidup \\
\hline
\end{tabular}

Table 3 Hasil pengujian sensor DHT22 pada malam hari

\begin{tabular}{|c|c|c|c|c|}
\hline \multirow{2}{*}{ No } & $\begin{array}{c}\text { Detik } \\
\text { (Sekon) }\end{array}$ & $\begin{array}{c}\text { DHT22 } \\
\text { (Celcius) }\end{array}$ & $\begin{array}{c}\text { LCD } \\
\text { (Indkator) }\end{array}$ & $\begin{array}{c}\text { Kipas } \\
\text { (Pendingin) }\end{array}$ \\
\hline 1 & 0 & 27.00 & Off & Mati \\
\hline 2 & 10 & 27.10 & Off & Mati \\
\hline 3 & 20 & 27.20 & Off & Mati \\
\hline 4 & 30 & 27.30 & Off & Mati \\
\hline 5 & 40 & 27.50 & Off & Mati \\
\hline 6 & 50 & 27.70 & Off & Mati \\
\hline 7 & 60 & 28.00 & Off & Mati \\
\hline 8 & 70 & 28.20 & On & Hidup \\
\hline 9 & 80 & 28.30 & On & Hidup \\
\hline 10 & 90 & 28.50 & On & Hidup \\
\hline 11 & 100 & 28.70 & On & Hidup \\
\hline 12 & 110 & 28.80 & On & Hidup \\
\hline 13 & 120 & 29.10 & On & Hidup \\
\hline
\end{tabular}

\section{Pengujian dan Analisa Alat Secara Keseluruhan Pada Laboraturium}

Berdasarkan pada hasil pengujian keseluruhan sistem yang dilakukan dalam ruangan Laboratorium pada saat mahasiswa beraktifitas belajar mengajar tabel pengujian dapat dilihat sebagai berikut.

Table 4. Pengujian alat keseluruhan dalam ruangan LEB saat mahasiswa beraktifitas

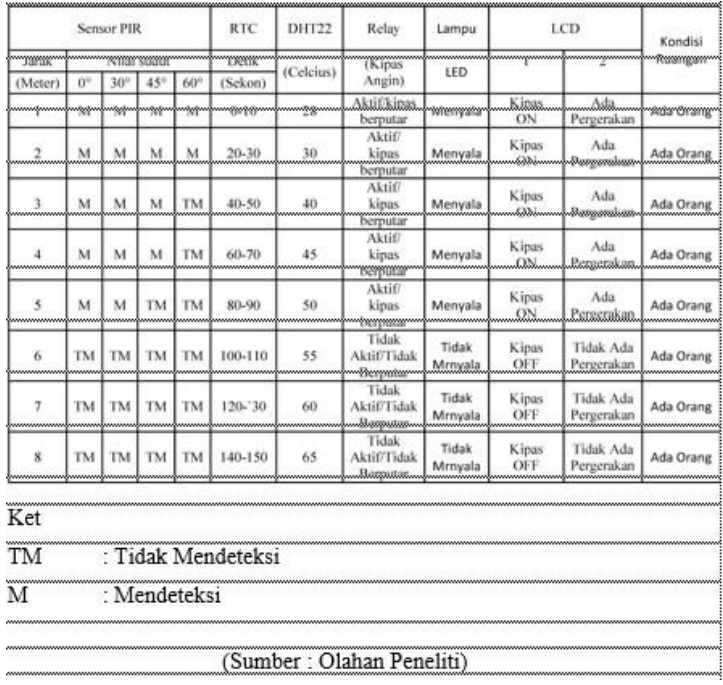

\section{KESIMPULAN}

Berdasarkan hasil penelitian yang telah dilakukan dapat ditarik kesimpulan sebagai berikut. 
1. Sistem pengontrolan suhu dalam ruangan yang dirancang mengunakan komponen utama terdiri dari mikrokontroler, sensor suhu, sensor gerak, modul RTC, LCD, relay, dan kipas. Dapat bekerja secara otomatis.

2. Sistem ini dapat membantu pihak kampus dalam mengontrol suhu dan mendeteksi gerakan dalam ruangan secara otomatis sehingga lebih efisien

3. Pengujian sesor PIR dengan jarak 1-5 meter dengan waktu yang digunakan dari 0-90 detik sensor masi mendeteksi adanya pergerakan, dengan adanya pergerakan yang terdeteksi oleh sensor PIR maka Relay aktif kipas berputar, kemudian $L C D$ sebagai indikator menampilkan kipas $O N$ dan ada pergerakan keterangan ruangan sedang ada orang. pengujian sensor PIR terhadap kepekaan sudut sekeliling ruangan, pengujian dimulai dari nilai sudut $0^{\circ}-45^{\circ}$ 1-4 meter PIR masih mendeteksi adanya Pergerakan. Selain itu pengujian sensor DHT22 dengan suhu normal $28^{\circ} \mathrm{C}$

\section{Saran}

1. Untuk penilitian selanjutnya, bisa mengantikan pendingin kipas $D C$ mengunakan kipas yang umumnya dipakai/AC agar kecepatan dapat diatur sesuai keinginan keberadaan orang dalam ruangan. Kemudian indikator $L E D$ dapat diubah mengunakan indikator berupa bunyi/suara sesuai keinginan.

2. Untuk pengembangan sistem dapat di buat dengan menambahkan pengontrolan yang terhubung pada SIM Card bisa melalui sms atau internet agar pengontrolan bisa dilakukan kapan dan dimana saja

3. Perlu adanya tampilan visual suhu pada aplikasi agar dapat di monitoring secara efisien

\section{DAFTAR PUSTAKA}

Abdullah, Masthura., Sistem Pemberian Nutrisi Dan Penyiraman Tanaman Otomatis Berdasarkan Real Time Clock Dan Tingkat Kelembaban Tanah Berbasis Mikrokontroler Atmega32, Jurnal Ilmu Fisika dan Teknologi, Vol. 2, No. 2 , 2018, 33 41, ISSN: 2580-6661

A. Ambarita, (2020), Analisys dan pengembangan sistem infomasi pendekatan model driven, Gosyen Publishing.

Arief Goeritno, D.J.Nugroho, R.yatim (2014): Implementasi Sensor DHT11 Untuk Pengkondisian Suhu dan Kelembapan Relatif Berbantuan Mikrokontroler, Seminar Nasional Sains dan Teknologi, TE-009. ISSN: 2407-1846

Deni Prasetiyanti (2016): Analisis Sistem Informasi Akuntasi Penjualan Kredit di PT Eka Timur Raya Purwodadi Pasuruan, (JRMA). ISSN : 233756xx. Volume : xx. Nomor: xx.

Dias Prihatmoko (2016): Perancangan dan Implementasi pengontrolan suhu ruangan Berbasis Mikrokontroller Arduino Uno, Jurnal SIMETRIS, Vol 7 No 1 April 2016

Future Electronics, (dalam Walidian, Mitra., I.Devi Sara., M.Syukri, 2018): Perancangan Sistem Penerangan LED Sebagai Sumber Cahaya Pada Pengijian Modul Surya, Jurnal Teknik Elektro, vol.3 No.2 2018.

Hannif Izzatul Islam, N.Nabilah, S.Sa'id Atsaurry, D.H.Saputra, G.M.Pradipta, A.Kurniawan, H.Syafutra, Irmansyah, Irzaman., Sistem Kendali Suhu Dan Pemantauan Kelembaban Udara Ruangan Berbasis Arduino Uno 
Dengan Menggunakan Sensor Dht22

Dan Passive Infrared (Pir), Prosiding Seminar Nasional Fisika (E-Journal) SNF2016, volume v- oktober, 2016, ISSN: 2339-0654-ISSN: 2476-9398

Dina Khusnia, Berliana Kusuma Riasti, Pembuatan Website Profil Sekolah Menengah Pertama Negeri 1 Kalitidu Bojonegoro, IJNS - Indonesian Journal on Networking and Security Volume 3 No 1 - Januari 2014, ISSN: 2302-5700 (Print) 2354-6654 (Online)

Hub, Project. (2016), Temperature Monitoring with DHT22 \& Arduino.http://create.arduino.cc/proj ecthub/attari/temperaturemonitoringwith-dht22-arduino-15b013.

(Akses: 01 September 2020)

Menteri Kesehatan Republik Indonesia. Keputusan (Menkes) Mentri kesehatan republic Indonesia Nomor 1405/Menkes/SK/XI/2002 Tentang Persyaratan Kesehatan Lingkungan Kerja Perkantoran dan Industri, Jakarta (2002). 